\title{
AVALIAÇÃO E CARACTERIZAÇÃO DOS IMÓVEIS URBANOS SITUADOS ACIMA DA ESTRADA FÉRREA ALTA SOROCABANA NO MUNICÍPIO DE PRESIDENTE PRUDENTE/SP
}

\author{
Mayara Cristina de Paula Felipe ${ }^{1}$, Hudson Matheus Carvalho Santos ${ }^{2}$ \\ ${ }^{1}$ Universidade Estadual Paulista - FCT/UNESP. Curso de Geografia, Presidente Prudente - SP. Curso de especialização \\ técnica em Geoprocessamento da ETEC Prof. Dr. Antônio Eufrásio de Toledo. ${ }^{2}$ Universidade Estadual Paulista - \\ UNOESTE. Curso de Engenharia Civil, Presidente Prudente - SP. Curso de especialização técnica em \\ Geoprocessamento da ETEC Prof. Dr. Antônio Eufrásio de Toledo. E-mail: may-cris@hotmail.com
}

\section{RESUMO}

O município de Presidente Prudente teve sua expansão relacionada diretamente com a implantação da estrada de ferro Alta Sorocabana. Esta foi responsável pela instalação dos primeiros núcleos habitacionais da cidade, aumentando o contingente populacional em virtude das atividades consequentes da ferrovia, como o comércio, banco, entre outras. Todavia, a expansão territorial do município foi altamente segregativa, para as áreas com topografia mais íngremes foram direcionadas as populações de baixo poder aquisitivo (zona leste), por outro lado, as áreas mais planas foram ocupadas pelas classes que possuíam um poder aquisitivo maior (Zona Oeste). Contudo, este estudo buscou identificar as influências dos fatores como declividade, acessibilidade e infraestrutura no valor do metro quadrado construído da área além-linha (zona leste e norte); procurou obter a mesma variável para alguns bairros da zona oeste e sul, com o objetivo de identificar se a área além-linha ainda hoje sofre de marginalização.

Palavras-chave: Estrada Férrea. Expansão Territorial. Segregação Socioespacial. Zona Leste. Avaliação de Imóveis.

\section{CHARACTERIZATION AND EVALUATION OF URBAN PROPERTY LOCATED ABOVE THE HIGH ROAD IRON SOROCABANA THE MUNICIPALITY OF PRESIDENTE PRUDENTE-SP}

\begin{abstract}
The city of Presidente Prudente had its expansion directly related to the deployment Railroad High Sorocabana. This was responsible for the installation of the first housing units in the city, increasing the population quota because of the railroad consequential activities such as trade, bank, among others. However, the territorial expansion of the city was highly segregationist, or for areas with steeper topography were targeted populations with low purchasing power (east side), on the other hand, the smooth plains were occupied by classes that held power purchasing larger (West Zone). However, this study sought to identify the influences of factors such as slope, accessibility and infrastructure in the amount of square meters of built area beyond-line (east and north); sought the same variable to some neighborhoods in western and southern districts, with the goal of identifying the area beyond the line still suffers from marginalization.

Keywords: Railway Road. Territorial expansion. Socio-Spatial Segregation. East Zone. Real Estate Appraisal.
\end{abstract}


INTRODUÇÃO

O processo de ocupação do Oeste Paulista se intensificou com a expansão da cultura cafeeira no século XX, desse modo, "a marcha para oeste paulista" era liderada por grandes fazendeiros, os quais possuíam grande quantidade de terras na região, consequentemente tinham o domínio dos postos de administração pública, das sociedades bancarias e das ferrovias.

A expansão das plantações de café passou a exigir a construção de um meio transporte, mais precisamente as estradas férreas. Assim sendo, os trilhos das ferrovias começaram a avançar em direção ao interior do estado de São Paulo. Logo, no oeste paulista o café se estabeleceu simultaneamente à implantação das estradas de ferro, o que possibilitou a constituição de um sistema ferroviário importantíssimo para o estado, pois propiciou a instalação de uma rede de cidades (LEITE, 1972).

Dessa maneira, graças a expansão da cultura cafeeira ocorreu o surgimento de algumas cidade no Estado de São Paulo, como exemplo, Presidente Prudente, que se tornou a principal cidade da Alta Sorocabana.

A mesma surgiu da implantação de dois núcleos urbanos, as Vilas Goulart e Marcondes. A colonização a oeste pertencente ao coronel Goulart, era caracterizada como de investimentos mais baixos, isso propiciou inicialmente uma maior ocupação do espaço rural e urbano, pois os lotes eram mais baratos e muitas vezes para a sua ocupação era necessário apenas à autorização do coronel Goulart. Já a Vila Marcondes, possuía lotes com preços mais elevados, pois segundo Abreu (1972) apud Ykuta (2003, p.82) esse núcleo era "de caráter empresarial, com maior suporte financeiro, ao invés da atitude passiva de esperar compradores, investia com estudada propaganda para realizar negócios".

Contudo, a implantação da ferrovia propiciou o surgimento de um dualismo na cidade de Presidente Prudente, onde os bairros denominados além-linha sofreram de uma marginalização justificada por ser ocupada em sua grande maioria pela população de menor poder aquisitivo. Nesse sentido e diante do histórico local, houve a necessidade de desenvolver este estudo que tem como objetivo constatar a existência e influência dessa marginalização na valorização e nos preços dos imóveis situados acima da estrada de ferro Alta Sorocabana no município de Presidente Prudente. Vale destacar que este trabalho é parte do desdobramento das pesquisas realizadas para o desenvolvimento do Trabalho de Conclusão de Curso do Curso Técnico em Agrimensura da ETEC Prof. Dr. Antônio Eufrásio de Toledo. 


\section{METODOLOGIA}

Para o desenvolvimento da pesquisa foi utilizada a revisão bibliográfica dos principais conceitos abordados. Posteriormente iniciou-se os procedimentos referentes à avaliação de imóveis.

Para a avaliação dos imóveis o método utilizado foi o comparativo, este método consiste em obter o valor médio de um bem móvel ou imóvel a partir da comparação com outros do mesmo gênero ou semelhantes. Fiker (2008) afirma ser este método o mais recomendável para a avaliação de terrenos urbanos. Para obter os dados das transações utilizou-se anúncios de diversas imobiliárias de Presidente Prudente, estes foram coletados de novembro de 2013 à junho de 2014, procurou-se ter um cuidado redobrado na coleta das informações.

Além disso, foram realizados trabalhos de campo com o objetivo de entender as dinâmicas dos bairros da área de estudo, principalmente as questões referentes ao padrão construtivo, infraestrutura existente, além de outros aspectos que influenciam no valor de um imóvel.

\section{ZONA LESTE E NORTE DA CIDADE DE PRESIDENTE PRUDENTE}

A diferença na origem urbana de Presidente Prudente, como já citado, se manifestou na expansão territorial da cidade. Desse modo, observou que as áreas além-linha muitas vezes permanecerem pouco povoadas, por outro lado áreas mais distantes do centro urbanizaram-se, como pode ser observado na planta do ano de 1989 da cidade de Presidente Prudente (Figura 01).

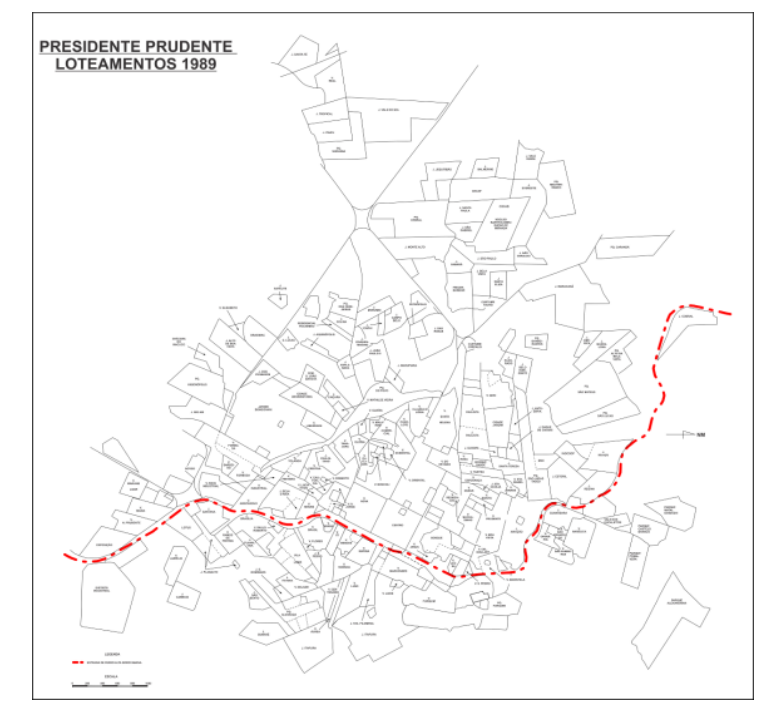

Figura 1. Loteamento na cidade de Presidente Prudente em 1989. Fonte: Adaptado de Sposito, E. (1990, p.111).

Nesse cenário, os aspectos como acessibilidade e externalidade influenciaram na valorização ou desvalorização dos imóveis. Para Harvey (1980) apud Sposito (1983, p.91-92), a acessibilidade diz respeito as facilidades e/ou dificuldades para ter acesso à determinadas 
atividades essenciais, como emprego, recursos, serviços de bem estar, entre outros. Já por externalidade, entende-se o conjunto de implicações decorrentes "da alocação de atividade, serviços ou instituições, etc., que afetam a nossa localização, trazendo benefícios ou incômodos, sem que possamos decidir sobre isto, ou por eles estejamos pagando diretamente".

Os imóveis situados na área além-linha, zona leste e norte, atualmente apresentam uma acessibilidade, em geral, regular. Embora, haja alguns equipamentos públicos situados nos bairros afastados, convém frisar, que eles não são suficientes para atender a demanda. Em relação à externalidade os bairros localizados na área de estudo apresentam normalmente casas que variam entre baixo e médio padrão construtivo. Ademais, observou-se que nessa porção existe um histórico de empreendimentos instalados que proporciona sua desvalorização, o mais destacado é a instalação de grande parte dos antigos locais de disposição de resíduos sólidos urbanos. Ressaltando, que se trata de uma zona que possui uma declividade acentuada o que também influencia no valor do imóvel.

\section{AVALIAÇÃO DOS IMÓVEIS}

Utilizando o método comparativo e posteriormente a operação matemática média, obtevese o valor médio do metro quadrado $\left(\mathrm{m}^{2}\right)$ construído por bairro (Figura 02). Vale ressaltar, que além dos bairros além-linha foram coletados dados de alguns loteamentos da zona oeste e sul, sendo eles: COHAB, Jardim Novo Bongiovani, Jardim Maracanã, Jardim Vale do Sol, Residencial Maré Mansa, Parque Residencial Mediterrâneo e Residencial São Paulo, com o propósito de realizar uma análise comparativa.

Analisando os resultados adquiridos, observou-se que as concepções históricas em relação à área além-linha influenciam na procura e consequentemente no valor dos imóveis presentes nessa porção. Ressaltando que os dez bairros com o metro quadrado mais caro foram: Vila Marcondes, Residencial Jarina, Jardim Itapura II, Condomínio Residencial Atalaia, Jardim Cobral, Condomínio Residencial Bela Vista, Residencial Itapuã, Jardim Itapura I, Residencial III Milênio, Jardim São Pedro, Jardim Santa Filomena. Já as áreas com metro quadrado mais barato estiveram presentes nos seguintes bairros: Jardim Santa Marta, Parque Novo Alvorada, Vila Operaria, Vila Rainho, Vila Iti, Vila Aurélio, Jardim Santa Monica, Jardim Morada do Sol, Jardim Humberto Salvador, Vila Paulo Roberto e Jardim Brasília (Figura 03). 


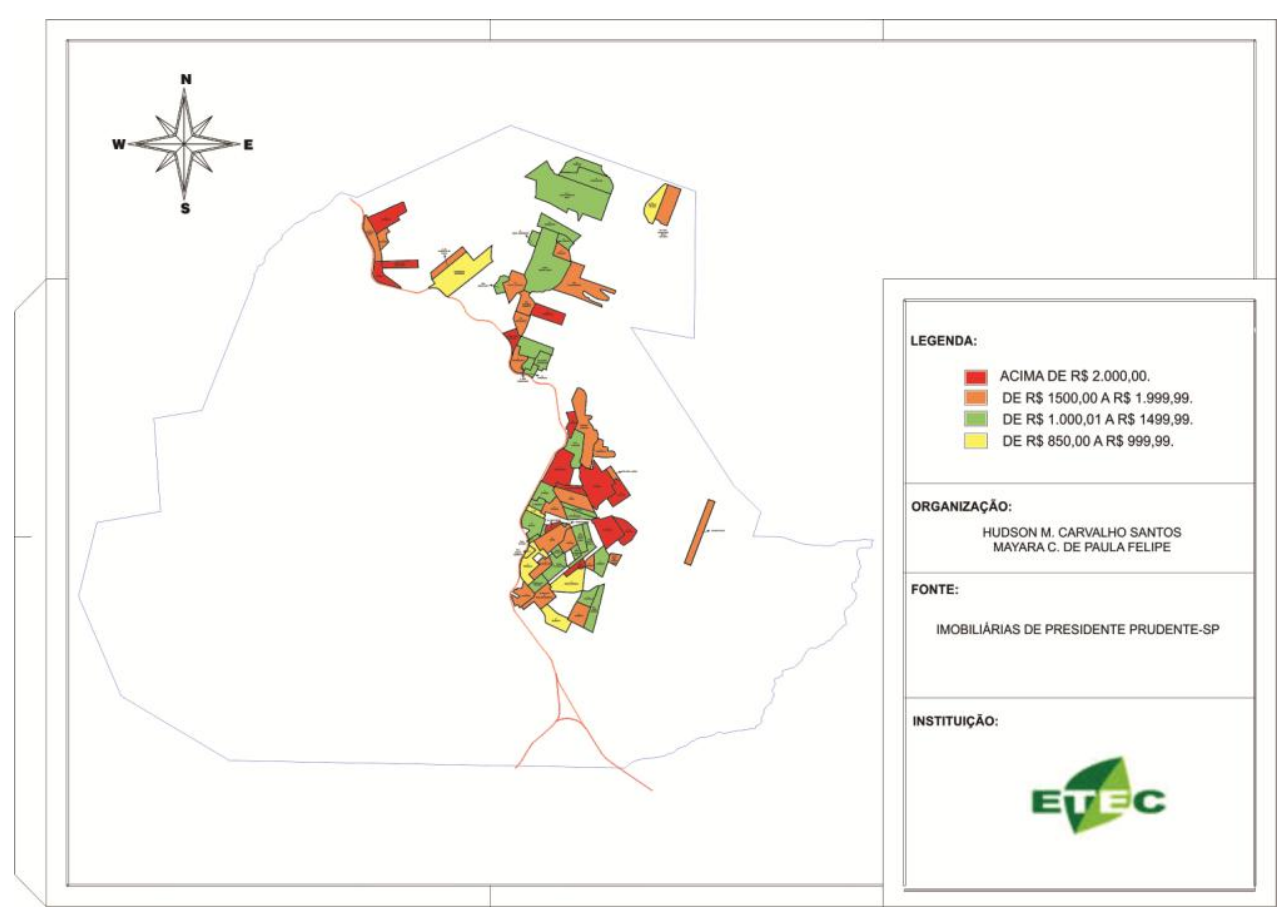

Figura 2. Média do $\mathrm{m}^{2}$ construído dos bairros além-linha de Presidente Prudente, 2014.

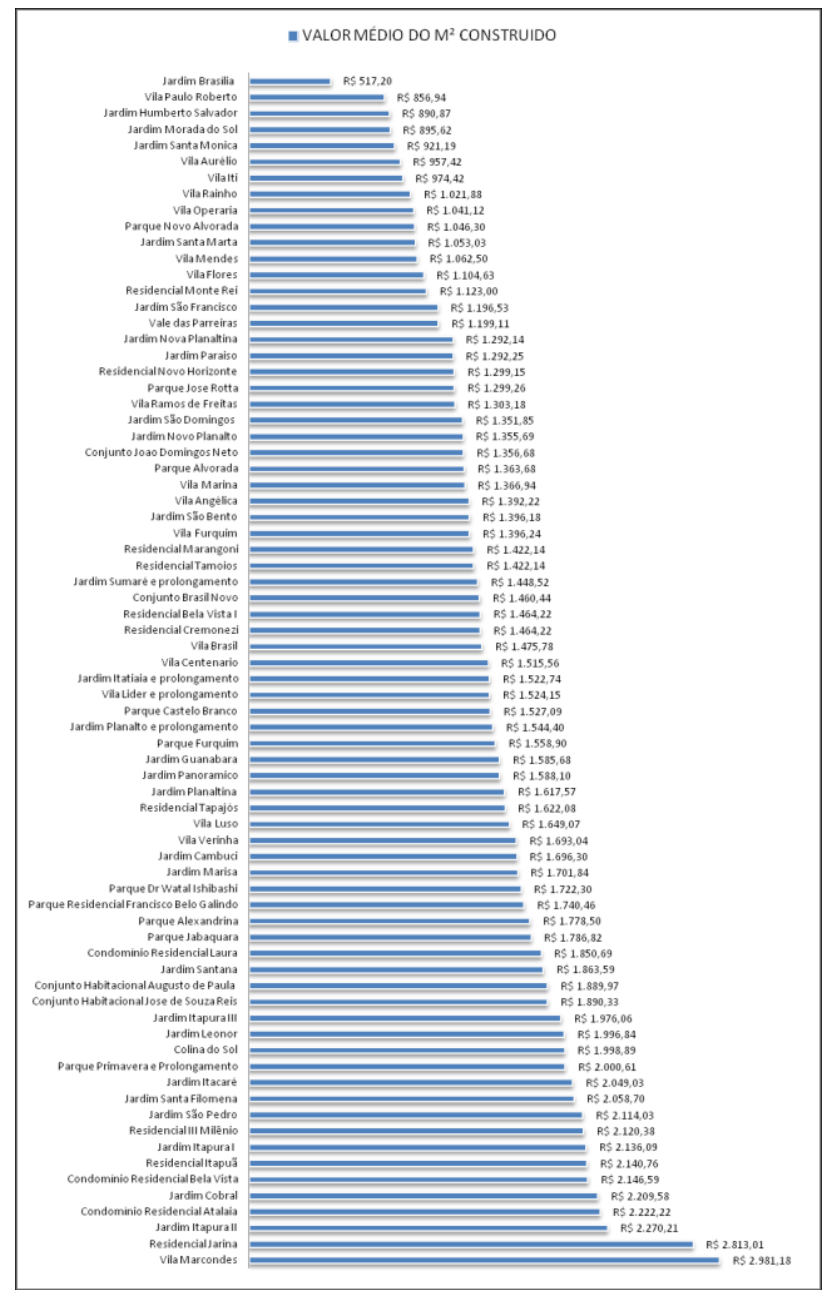

Figura 3. Média do $\mathrm{m}^{2}$ construído dos bairros da área de estudo.

Em relação ao bairro com o metro quadrado construído mais barato, o Jardim Brasília $R \$ 517,20$ - esse foi projetado em 1965, está localizado na porção leste do município e limita-se 
com os bairros Vila Ramos de Freitas, Jardim Planaltina, Jardim Santana, Vila Flores e Vila Líder, com área total de $195.009,1072 \mathrm{~m}^{2}$ se constitui de cerca de 562 lotes. Por outro lado, a Vila Marcondes possui o metro quadrado construído mais caro - $\mathrm{R} \$ 2.981,18$. Este que foi o primeiro bairro a ser implantado nesta porção da cidade mais precisamente no ano de 1917 com 194 lotes. Essa vila tem como bairros limítrofes as Vilas Furquim, Marisa, Luso e o Jardim Santa Filomena.

Com o objetivo de comparar as médias dos bairros além-linha com outros bairros da zona oeste e sul, obtivemos a média do metro quadrado construído de oito bairros (Tabela 01).

Tabela 2. Média do $\mathrm{m}^{2}$ construído de bairros da Zona Oeste e Sul, 2014.

\begin{tabular}{c|c}
\hline BAIRROS & MÉDIA DO $\mathbf{M}^{2}$ CONSTRUÍDO \\
\hline Ana Jacinta & $\mathrm{R} \$ 2.903,13$ \\
\hline COHAB & $\mathrm{R} \$ 2.796,83$ \\
\hline Jd. Maracanã & $\mathrm{R} \$ 2.975,44$ \\
\hline Jd. Novo Bongiovani & $\mathrm{R} \$ 2.326,92$ \\
\hline Jd. Vale do Sol & $\mathrm{R} \$ 2.978,30$ \\
\hline Pq. Resid. Mediterrâneo & $\mathrm{R} \$ 2.874,85$ \\
\hline Resid. Maré Mansa & $\mathrm{R} \$ 3.064,57$ \\
\hline Resid. São Paulo & $\mathrm{R} \$ 2.832,47$ \\
\hline
\end{tabular}

Contudo, foi possível verificar que as médias dos bairros da zona oeste e sul são superiores a média dos bairros além-linha. Todavia, nos últimos anos tem se observado a valorização de algumas áreas além-linha, pois passou a existir um interesse dos construtores para determinadas áreas, em virtude dos projetos de financiamentos lançados pelo governo Federal, isso fez com que diversos empresários do ramo da construção civil passassem a investir na edificação de casas voltadas para o financiamento, como o que vem ocorrendo no Jardim Cobral, dessa forma, o construtor compra um terreno, o desmembra e constrói duas casas, sendo dessa maneira, um empreendimento altamente vantajoso.

\section{DISCUSSÃO}

O solo possui um valor de uso, pois é indispensável à produção de mercadorias, uma vez que, é a base física onde o capital é transformado em bens de produção, além disso, é indispensável à reprodução da força de trabalho, visto que é sobre o solo que se constrói as habitações (SPOSITO, 1983).

Duas esferas atuam sobre o espaço urbano, controlando, regendo, combinando os fatores, ou seja, determinando e direcionando o crescimento territorial urbano, sendo essas a ação pública e privada. Sposito (1983, p.176) destaca que: 
A cidade é então organizada pelo capital e para a reprodução do capital. Ocorre que esse processo de organização do espaço para o capital não se desenvolve espontaneamente, ao contrário resulta da prática de alguns segmentos da sociedade.

Desse modo, a análise da iniciativa privada no processo de produção do solo, de acordo com Sposito (1983), permite identificar três agentes desse processo, sendo eles: os proprietários fundiários, os incorporadores e os corretores imobiliários. Nesse contexto, a partir da década de 1970 a produção do espaço urbano em Presidente Prudente caracterizou-se por ser empresarial, em oposição à forma de organização espacial que vinha sendo praticada até então.

Essas alterações no processo de produção urbana fez com que aumentasse os preços dos terrenos, pois aumentaram os investimentos em virtude da regularização, publicidade e implantação das benfeitorias, por conseguinte, o aumento dos tributos fez com que a possibilidade de adquirir um lote se tornasse quase impossível para os cidadãos de baixo poder aquisitivo, sendo a sua única possibilidade de comprar uma moradia os programas habitacionais COHAB, CECAP e PROFILURB.

Contudo, esta ação fortaleceu a segregação espacial da população, a partir de seus extratos de renda. Tendo a ação pública um papel fundamental nesse processo, pois era ela que determinava os espaços que receberiam os investimentos, ocasionando a sua valorização em relação aos demais. Ou seja, o poder público promovia, através dessa valorização diferenciada do espaço, a segregação social. Portanto, em Presidente Prudente "[...] o chão urbano vai sendo valorizado, o que vale dizer, segregado socialmente. É a produção e distribuição desigual do urbano" (SPOSITO, 1983, p.222).

\section{CONCLUSÕES}

O processo de expansão territorial em Presidente Prudente foi altamente segregativo, restando a população de baixo poder aquisitivo somente as áreas periféricas. Enquanto que as classes sociais mais elevadas ocupou as melhores porções tanto relacionadas ao relevo, ou seja, as áreas mais planas especificamente os topos, como também relacionadas às áreas mais equipadas por infraestrutura, ou seja, próximo as vias de acesso, comércio, sem falar na instalação de sistema de esgoto, água encanada, energia elétrica e outras benfeitorias.

Contudo, diante do que foi exposto, conclui-se que o mito além-linha ainda existe em meio ao subconsciente da maioria dos prudentinos e também de moradores de cidades vizinhas, este fator ainda respinga na imagem e consequentemente no valor de bens situados nesta área. 
Além disso, observou-se que mesmo com a prefeitura, órgãos públicos e particulares estejam investindo buscando a desmistificação de tal concepção e certa expansão para esta porção prudentina, alguns serviços básicos ainda demonstram-se ineficientes e com inúmeras falhas.

\section{REFERÊNCIAS}

FIKER, J. Manual de Avaliações e Perícias em Imóveis Urbanos. 3. ed. São Paulo: Pini, 2008. 149p.

IKUTA, F. A. A cidade e as águas: a expansão territorial urbana e a ocupação de fundos de vales em Presidente Prudente - SP. Presidente Prudente, 2003. 191f. Dissertação (Mestrado em Geografia) - Faculdade de Ciências e Tecnologia, Universidade Estadual Paulista, Presidente Prudente.

LEITE, J. F. A Alta Sorocabana e o espaço polarizado de Presidente Prudente. Presidente Prudente: Faculdade de Filosofia, Ciências e Letras, 1972.

SPOSITO, E. S. S. Produção e apropriação da renda fundiária urbana em Presidente Prudente. Tese de doutorado apresentada ao curso de Pós-Graduação em Geografia Humana da Faculdade de Filosofia, Letras e Ciências Humanas da Universidade de São Paulo. São Paulo, 1990. 229 p.

SPOSITO, M. E. B. O chão em Presidente Prudente: a lógica da expansão territorial urbana. Dissertação de Mestrado em Geografia. Rio Claro: Instituto de Geociências e Ciências Exatas, Universidade Estadual Paulista, 1983. 230 p. 